\title{
Long-Term Outcomes of a Multimodal Day-Clinic Treatment for Chronic Pain under the Conditions of Routine Care
}

\author{
Mira A. Preis, ${ }^{1}$ Elisabeth Vögtle, ${ }^{1}$ Nele Dreyer, ${ }^{2}$ Stefanie Seel, ${ }^{2}$ Ruth Wagner, ${ }^{3}$ \\ Klaus Hanshans, ${ }^{3}$ Renate Reyersbach, ${ }^{3}$ Christoph Pieh, ${ }^{4}$ Andreas Mühlberger, ${ }^{2}$ \\ and Thomas Probst ${ }^{4}$ \\ ${ }^{1}$ Georg-Elias-Müller Institute for Psychology, Georg-August University Göttingen, Göttingen, Lower Saxony, Germany \\ ${ }^{2}$ Institute for Psychology, Regensburg University, Regensburg, Germany \\ ${ }^{3}$ Hospital Barmherzige Brüder, Regensburg, Germany \\ ${ }^{4}$ Department for Psychotherapy and Biopsychosocial Health, Danube University Krems, Krems, Austria
}

Correspondence should be addressed to Thomas Probst; thomas.probst@donau-uni.ac.at

Received 12 December 2017; Revised 21 February 2018; Accepted 6 March 2018; Published 1 April 2018

Academic Editor: Fletcher A. White

Copyright ( 2018 Mira A. Preis et al. This is an open access article distributed under the Creative Commons Attribution License, which permits unrestricted use, distribution, and reproduction in any medium, provided the original work is properly cited.

Chronic pain has high prevalence rates and is one of the top causes of years lived with disability. The aim of the present study was to evaluate the long-term effects of a multimodal day-clinic treatment for chronic pain. The sample included 183 chronic pain patients (114 females and 69 males; $53.3 \pm 9.8$ years) who participated in a four-week multimodal day-clinic treatment for chronic pain. The patients' average current pain intensity (NRS), sensory and affective pain (Pain Perception Scale), and depression and anxiety (HADS) were assessed at pre- and posttreatment, as well as at three follow-ups (one month, six months, and twelve months after completion of the treatment). Multilevel models for discontinuous change were performed to evaluate the change of the outcome variables. Improvements from pretreatment to posttreatment and from pretreatment to all follow-ups emerged for pain intensity (NRS; $0.54 \leq d \leq 0.74$ ), affective pain (Pain Perception Scale; $0.24 \leq d \leq 0.47$ ), depression (HADS; $0.38 \leq d \leq 0.53$ ), and anxiety (HADS; $0.26 \leq d \leq 0.43$ ) (all $p<0.05$ ). Sensory pain as assessed with the Pain Perception Scale did not show any significant change. Patients suffering from chronic pain benefited from the multimodal pain treatment up to twelve months after completion of the treatment.

\section{Introduction}

Chronic pain is a major health care problem. A recent review and meta-analysis including 86 studies found an average prevalence estimate of $31 \%$ [1]. Chronic pain is a disabling condition with multidimensional impact on patients, their families, and daily life [2], as well as on work-related variables like loss of employment, early retirement, sick leave, or loss of productivity [3-5]. In the last years, pain constantly is one of the top causes of years lived with disability [6]. Lee et al. [7] reported that self-efficacy, psychological distress, and fear contribute to the process how pain leads to disability.

The interaction between pain and these psychological variables as well as mental disorders like depression and anxiety [8,9] makes multimodal treatments necessary. Multidisciplinary treatments for chronic pain have been found to be more effective than single-discipline treatments already in 1992 [10] and 2001 [11]. A more recent systematic meta-analysis including 41 randomized controlled trials (RCTs) reported that multidisciplinary treatment for pain is effective to reduce pain and disability and had positive influences on work status compared to physical therapy alone or treatment as usual [12]. The strength of RCTs is their internal validity, but the external validity can be limited [13]. In the area of chronic pain, for example, it has been found that patients "who were randomised were different, in a number of ways, from the entire eligible patient population that was originally identified" (p. 98) [14]. Therefore, there is a broad consensus that interventions should show their 
efficacy in RCTs under controlled conditions and their effectiveness under clinically representative conditions [15]. With regard to multimodal therapy for patients with chronic pain, there is some evidence for its effectiveness under clinically representative conditions as well [16-27].

Despite these effects of pain management treatments in controlled and clinically representative contexts, Wilson [28] stated in a recent critical review that more research on the long-term outcomes and the sustaining effects of such programs for chronic pain is necessary.

To further evaluate the long-term effectiveness of multidisciplinary treatments for chronic pain under the conditions of routine care, the present study investigated the effects of a multimodal day-clinic treatment for chronic pain on aspects of pain (pain intensity and affective and sensory pain) and on depression and anxiety. We hypothesized that the multidisciplinary treatment is effective up to 12 months after treatment.

\section{Materials and Methods}

2.1. Sample. The sample consisted of 183 patients (114 females and 69 males; mean age of $53.3 \pm 9.8$ years) who participated in the multimodal day-clinic treatment for chronic pain at the Hospital Barmherzige Brüder Regensburg (Germany) from 2010 to 2013. All patients fulfilled the criteria for the ICD-10 diagnosis of a chronic pain disorder with somatic and psychological factors (F45.41). 75.4 percent of the patients fulfilled the criteria for at least one other psychiatric disorder, with depression (57.9 percent) and anxiety disorders (22.4 percent) being the most frequently diagnosed comorbidities. The four most frequent medical diagnoses according to ICD-10 were dorsalgia (M54), other disorders of the muscle (M62), other headache syndromes (G44), and other unspecified dorsopathies (M53). The diagnoses were made by the clinic team. With regard to Von Korffs' chronic pain grades [29] that use pain intensity and pain-related disability to grade pain into four hierarchical classes (grade I, low disability-low intensity; grade II, low disability-high intensity; grade III, high disability-moderately limiting; and grade IV, high disability-severely limiting), the majority of the patients showed high disability and moderate-to-high limiting with four percent of the patients classified as grade 1, 16.2 percent as grade II, 29.5 percent as grade III, and 50.3 percent as grade IV. All patients provided written informed consent before their participation.

2.2. Psychometric Instruments. The following self-rating instruments were given at pre- and posttreatment, as well as one month, six months, and twelve months after completion of the treatment. At the three-month follow-up assessment, the clinic sent a paper and pencil version of the questionnaires by post to the patients. After completing the questionnaires, the patients sent them back to the clinic.

2.2.1. Pain Intensity. The participants rated the average current pain intensity on a Numerical Rating Scale (NRS) from 0 (no pain) to 10 (worst imaginable pain).
2.2.2. Pain Perception Scale. The Pain Perception Scale (SES [30]) includes 24 items that describe the affective (14 items, e.g., nagging and unbearable) and sensory qualities of pain (10 items, e.g., hot and pulsative). Each item is rated on a 4-point scale from 0 (not appropriate) to 3 (appropriate). Both scales show good internal consistencies, with Cronbach's $\alpha=0.92$ for the affective scale and $\alpha=0.81$ for the sensory scale [30].

2.2.3. Depression and Anxiety. Designed for clinical populations suffering from somatic symptoms, the German version of the Hospital Anxiety and Depression Scale (HADS) was used to assess anxiety and depression in the past week [31, 32]. The HADS includes 14 items, of which seven assess anxiety (e.g., I feel tense or overstrung), whereas the other seven items measure depression (e.g., I am happy). All items are rated on a 4-point scale. Both scales reach satisfactory internal consistencies (Cronbach's $\alpha=0.80$ for both depression and anxiety [31]).

2.3. Procedure/Treatment. At the Hospital Barmherzige Brüder Regensburg (Germany), an interdisciplinary team of psychologists, physicians, physical therapists, occupational therapists, and social workers carried out the 4-week multimodal day-clinic treatment for chronic pain. The treatment is based on cognitive-behaviour therapy for pain "Marburger Schmerzbewältigungsprogramm" [33]. Each of the 4 treatment weeks proceeded according to the same schedule that lasted from Monday to Friday (8.00 a.m. to 4.00 p.m.; on Fridays: 8.00 a.m. to 1.15 p.m.) and was composed of different treatment elements including medical and psychological modules as well as physical therapy (see Figure 1 for an overview of the weekly schedule). Psychological group sessions included psychoeducation and comprehension of the biopsychosocial pain model, directing the attention towards positive experiences, as well as relaxation techniques. The maximal group size was eight patients and continued throughout the program with the same patients (closed groups).

2.4. Statistics. SPSS 24 was used for the statistical analyses. Multilevel models for discontinuous change were performed to evaluate the progress of the outcome variables (pain intensity, affective pain, sensory pain, depression, and anxiety) between the five assessment points. According to Göllner et al. [34], four contrast variables were created to investigate the course of the outcomes from (1) pretreatment to the end of treatment, (2) pretreatment to 1-month follow-up, (3) pretreatment to 6-month follow-up, and (4) pretreatment to 12-month follow-up. All multilevel models were performed with the full maximum likelihood estimation, and an unstructured variance-covariance matrix was selected. The multilevel models included two levels: assessments as level 1 and patients as level 2 . The statistical tests were performed twotailed, and the statistical significance value was set to $p<0.05$. Moreover, effect sizes $(d)$ were calculated with the means and standard deviations at the five assessment points as follows: 


\begin{tabular}{|c|c|c|c|c|c|}
\hline & Monday & Tuesday & Wednesday & Thursday & Friday \\
\hline $8.00-9.00$ a.m. & \multicolumn{5}{|c|}{$\begin{array}{l}\text { Medical/psychological component } \\
\text { (ward round, medical education, and medically oriented exchange of experience) }\end{array}$} \\
\hline $9.00-10.00$ a.m. & \multicolumn{4}{|c|}{$\begin{array}{c}\text { Psychological component } \\
\text { (psychological education and psychologically oriented exchange of } \\
\text { experience) }\end{array}$} & $\begin{array}{l}\text { Medication- } \\
\text { oriented } \\
\text { consultation hou }\end{array}$ \\
\hline $10.00-11.30$ a.m. & Aquatherapy & Dance therapy & Dance therapy & Aquatherapy & Dance therapy \\
\hline 11.30 a.m. -1.15 p.m. & \multicolumn{4}{|c|}{$\begin{array}{l}\text { Lunch break } \\
\text { Individual consultations with physicians/psychologists/ } \\
\text { physiotherapists }\end{array}$} & Conclusion \\
\hline 1.15-2 p.m. & \multicolumn{4}{|c|}{ Relaxation techniques } & \\
\hline 2.30-4 p.m. & \multicolumn{4}{|c|}{ Physiotherapy/muscle training } & \\
\hline
\end{tabular}

FIGURE 1: Weekly schedule of the multimodal treatment program.

TABLe 1: Sample size $(n)$, means $(M)$, and standard deviations (SD) of the measures per assessment point.

\begin{tabular}{|c|c|c|c|c|c|c|c|c|c|c|c|c|c|c|c|}
\hline & \multicolumn{3}{|c|}{ Pretreatment } & \multicolumn{3}{|c|}{ End of treatment } & \multicolumn{3}{|c|}{ 1-month follow-up } & \multicolumn{3}{|c|}{ 6-month follow-up } & \multicolumn{3}{|c|}{ 12-month follow-up } \\
\hline & $n$ & $M$ & SD & $n$ & $M$ & SD & $n$ & $M$ & SD & $n$ & $M$ & SD & $n$ & $M$ & SD \\
\hline NRS & 183 & 51 & 166 & 176 & 5.53 & 85 & 168 & 5.28 & 188 & 152 & 5.61 & 1.91 & 123 & 5.48 & 1.95 \\
\hline SES: a & 168 & 4 & & 1 & 53.79 & 25 & & 49 & 27 & & 55.11 & 29.29 & 97 & 50.17 & 27.61 \\
\hline SES: & 168 & 66.90 & 26.48 & 152 & 64.65 & 26 & 145 & 64.37 & 26 & 13 & 66 & 28.18 & 96 & 65.15 & 26.75 \\
\hline ressi & 180 & 10.34 & 4.20 & 176 & 8.13 & 4.59 & 168 & 8.42 & 4.76 & 155 & 8.45 & 4.94 & 122 & 8.76 & 5.03 \\
\hline HADS: anxiety & 180 & 10.49 & 4.24 & 176 & 8.81 & 4.34 & 168 & 8.66 & 4.49 & 156 & 9.39 & 4.67 & 118 & 9.05 & 4.05 \\
\hline
\end{tabular}

Note. NRS: Numeric Rating Scale; SES: Pain Perception Scale; HADS: Hospital Anxiety and Depression Scale.

$\left(M_{\text {pretreatment }}-M_{\text {posttreatment_or_follow-up }}\right) / \mathrm{SD}_{\text {pretreatment }}$. Effect sizes were calculated with the values given in Table 1. Furthermore, differences between the pretreatment values of the NRS and the posttreatment values of the NRS and differences between the pretreatment NRS scores and the follow-up NRS scores were computed. The differences were calculated only for those patients with available NRS scores at both assessment points to compute differences. Patients with an improvement $\geq 2$ points on the NRS were classified as patients with clinically important improvements [35].

\section{Results}

3.1. Dropout. Dropout rates differed between the measures. For the Numeric Rating Scale (NRS) that assessed the average current pain intensity, response rates ranged from $100 \%$ at pretreatment to $67.2 \%$ at 12 -month follow-up. Response rates concerning the Pain Perception Scale (SES [30]) that measured affective and sensory pain qualities ranged from $91.8 \%$ at pretreatment to $53 \%$ at 12 -month follow-up. Response rates regarding symptoms of anxiety and depression that were recorded by means of the Hospital Anxiety and Depression Scale (HADS [31]) reached from $98.4 \%$ at pretreatment to $64.5 \%$ at 12 -month follow-up. For a full overview of the dropout rates, see Table 1.

\subsection{Treatment Effects on Pain Characteristics}

3.2.1. Pain Intensity. The estimates of the multilevel model with pain intensity (numeric rating scale) as outcome are presented in Table 2. Reductions of pain intensity became statistically significant from pretreatment to the end of treatment $(d=0.59 ; p<0.001)$, from pretreatment to 1 -month follow-up $(d=0.74 ; p<0.001)$, from pretreatment to 6-month follow-up $(d=0.54 ; p<0.001)$, and from pretreatment to 1 -year follow-up $(d=0.62 ; p<0.001)$.

In addition, we calculated the percentage of patients who reached a reduction of at least two points on the NRS from pretreatment to the other assessment points. A pain reduction of 2 points or more on the NRS was reached by $34.1 \%$ at the end of the treatment, by $45.2 \%$ at $1-$ month follow-up, by $36.8 \%$ at 6 -month follow-up, and by $36.6 \%$ at 1-year follow-up. The percentages are in relation to the sample of patients with NRS scores at both assessment points.

3.2.2. Affective Pain. Table 3 summarizes the results of the multilevel model with affective pain (Affective scale of the Pain Perception Scale [30]) as outcome. It can be seen that the affective component of pain was significantly improved from pretreatment to the end of treatment 
TABLe 2: Results of the multilevel model for discontinuous change with pain intensity as outcome $(N=183)$.

\begin{tabular}{|c|c|c|c|c|c|}
\hline Parameter & Estimate & SE & $\mathrm{df}$ & T-statistic & $p$ \\
\hline Intercept (pretreatment) & 6.51 & 0.12 & 183.00 & 53.22 & $<0.001$ \\
\hline Change from pretreatment to the end of treatment & -0.97 & 0.12 & 178.66 & -7.83 & $<0.001$ \\
\hline Change from pretreatment to 1 -month follow-up & -1.18 & 0.14 & 165.87 & -8.58 & $<0.001$ \\
\hline Change from pretreatment to 6-month follow-up & -0.85 & 0.15 & 168.24 & -5.74 & $<0.001$ \\
\hline Change from pretreatment to 1 -year follow-up & -0.99 & 0.16 & 159.29 & -6.12 & $<0.001$ \\
\hline
\end{tabular}

Table 3: Results of the multilevel model for discontinuous change with affective pain as outcome $(N=174)$.

\begin{tabular}{|c|c|c|c|c|c|}
\hline Parameter & Estimate & SE & df & T-statistic & $p$ \\
\hline Intercept (pretreatment) & 60.93 & 1.90 & 170.14 & 32.06 & $<0.001$ \\
\hline Change from pretreatment to the end of treatment & -7.88 & 1.58 & 159.14 & -4.98 & $<0.001$ \\
\hline Change from pretreatment to 1 -month follow-up & -12.08 & 1.96 & 157.33 & -6.17 & $<0.001$ \\
\hline Change from pretreatment to 6-month follow-up & -5.85 & 2.23 & 151.13 & -2.63 & 0.010 \\
\hline Change from pretreatment to 1 -year follow-up & -7.96 & 2.30 & 148.83 & -3.46 & 0.001 \\
\hline
\end{tabular}

TABLE 4: Results of the multilevel model for discontinuous change with sensory pain as outcome $(N=174)$.

\begin{tabular}{lcccc}
\hline Parameter & Estimate & SE & df & T-statistic \\
\hline Intercept (pretreatment) & 66.58 & 2.03 & 170.00 & 32.77 \\
Change from pretreatment to the end of treatment & -2.24 & 1.86 & 159.09 & -1.20 \\
Change from pretreatment to 1-month follow-up & -2.26 & 1.74 & 158.28 & -1.30 \\
Change from pretreatment to 6-month follow-up & 0.36 & 1.95 & 150.76 & 0.18 \\
Change from pretreatment to 1-year follow-up & 2.89 & 1.96 & 134.09 & 0.195 \\
\hline
\end{tabular}

TABLe 5: Results of the multilevel model for discontinuous change with depression as outcome $(N=183)$.

\begin{tabular}{|c|c|c|c|c|c|}
\hline Parameter & Estimate & SE & $\mathrm{df}$ & T-statistic & $p$ \\
\hline Intercept (pretreatment) & 10.37 & 0.31 & 182.04 & 33.32 & $<0.001$ \\
\hline Change from pretreatment to the end of treatment & -2.14 & 0.24 & 175.39 & -8.87 & $<0.001$ \\
\hline Change from pretreatment to 1 -month follow-up & -1.73 & 0.25 & 167.85 & -6.98 & $<0.001$ \\
\hline Change from pretreatment to 6 -month follow-up & -1.54 & 0.30 & 157.07 & -5.12 & $<0.001$ \\
\hline Change from pretreatment to 1 -year follow-up & -1.05 & 0.35 & 148.07 & -2.98 & 0.003 \\
\hline
\end{tabular}

$(d=0.29 ; p<0.001)$, from pretreatment to 1 -month follow-up $(d=0.47 ; p<0.001)$, from pretreatment to 6-month follow-up $(d=0.24 ; p=0.010)$, and from pretreatment to 1 -year follow-up $(d=0.44 ; p=0.001)$.

3.2.3. Sensory Pain. The results of the multilevel model with sensory pain (Sensory scale of the Pain Perception Scale [30]) as outcome are shown in Table 4. No statistically significant changes emerged from pretreatment to the end of treatment $(d=0.08 ; p=0.231)$, from pretreatment to 1-month follow-up $(d=0.10 ; p=0.195)$, from pretreatment to 6-month follow-up $(d=0.03 ; p=0.856)$, and from pretreatment to 1 -year follow-up $(d=0.07 ; p=0.142)$.

\subsection{Treatment Effects on Psychological Variables}

3.3.1. Depression. Table 5 includes the results of the multilevel model with depression (Depression scale of the Hospital Anxiety and Depression Scale [31]) as outcome. All comparisons reached statistical significance: depression improved from pretreatment to the end of treatment $(d=0.53 ; p<0.001)$, from pretreatment to 1 -month follow-up $(d=0.46 ; p<0.001)$, from pretreatment to 6 -month follow-up $(d=0.45 ; p<0.001)$, and from pretreatment to 1 -year follow-up $(d=0.38 ; p=0.003)$.

3.3.2. Anxiety. Results for the multilevel model with anxiety (Anxiety scale of the Hospital Anxiety and Depression Scale [31]) as outcome are given in Table 6. The significant results indicate that anxiety decreased from pretreatment to the end of treatment $(d=0.40 ; p<0.001)$, from pretreatment to 1 -month follow-up $(d=0.43 ; p<0.001)$, from pretreatment to 6-month follow-up $(d=0.26 ; p=0.004)$, and from pretreatment to 1 -year follow-up $(d=0.34 ; p=0.002)$.

\section{Discussion}

The aim of the present study was to evaluate the long-term effects of a multimodal day-clinic treatment for chronic pain on pain characteristics (pain intensity and sensory and affective pain) and associated psychological aspects (depression and anxiety). The 4 -week pain treatment significantly reduced the patients' pain intensity, depression, and anxiety, improved the appraisal of affective qualities of pain, and remained stable over a period of 12 months after 
TABLE 6: Results of the multilevel model for discontinuous change with anxiety as outcome $(N=182)$.

\begin{tabular}{|c|c|c|c|c|c|}
\hline Parameter & Estimate & SE & $\mathrm{df}$ & T-statistic & $p$ \\
\hline Intercept (pretreatment) & 10.52 & 0.31 & 181.62 & 33.52 & $<0.001$ \\
\hline Change from pretreatment to the end of treatment & -1.69 & 0.24 & 174.40 & -6.98 & $<0.001$ \\
\hline Change from pretreatment to 1 -month follow-up & -1.73 & 0.26 & 171.19 & -6.60 & $<0.001$ \\
\hline Change from pretreatment to 6 -month follow-up & -0.92 & 0.32 & 155.92 & -2.91 & 0.004 \\
\hline Change from pretreatment to 1 -year follow-up & -0.94 & 0.30 & 151.28 & -3.09 & 0.002 \\
\hline
\end{tabular}

completion of the treatment. There was no effect on the Sensory Pain scale of the Pain Perception Scale.

In the following paragraphs, we embed our results in the existing literature on the effectiveness of multimodal treatments for chronic pain under clinically representative conditions. When interpreting these benchmark comparisons, it is important to consider the following aspects as possible reasons for discrepant results. Different treatment durations (4 weeks in the present study and, e.g., in [26] versus 5 weeks in $[24,25])$, different treatment settings (e.g., day-clinic treatment in the present study and, e.g., in $[24,25]$ versus inpatient treatment in [17]), and different dropout rates (e.g., $80 \%$ [27] or 59\% [17] dropout at 1-year follow-up versus $<50 \%$ dropout at 1-year follow-up in the present study).

The patients' pain intensity improved from pre- to posttreatment with a medium effect size of $d=0.59$. This is comparable to the medium effect sizes of $d=0.64$ found by Hampel et al. [21], $d=0.6$ reported by Moradi et al. [22], and $d=0.51$ found by Ruscheweyh et al. [26]. However, Pieh et al. [24] and Pöhlmann et al. [25] reported larger effect sizes of $d=1.0$ and $d=0.69-0.98$, respectively, concerning the reduction of the pain intensity at the end of a 5-week multimodal day-clinic treatment for patients with chronic pain. Borys et al. [17] reported a higher effect size of $d=0.74$ at the end of 3-week inpatient treatment. Over a period of six and twelve months, pain intensity was improved in our study, which indicates that the patients could implement their acquired knowledge of the treatment in their everyday life and profit in the long term. With regard to Schütze et al. [27], the effect size at the six-month follow-up is comparable $(d=0.54$ versus $d=0.55)$, whereas the twelve-month follow-up effect size is smaller in the current study ( $d=0.62$ versus $d=0.95$ for $20 \%$ of the patients taking part in the follow-up in [27]). While Moradi et al. [22] $(d=0.7)$ and Pöhlmann et al. [25] (0.69-0.98) reported higher effect sizes at 6-month follow-up Ruscheweyh et al. [26] found a smaller long-term effect of $d=0.33$ at that time as did Hampel et al. [21] $(d=0.37)$. The effect size for pain intensity at 12-month follow-up in the current study $(d=$ 0.62) was higher than the one found by Borys et al. [17] $(d=0.20)$. With regard to Farrar et al. [35] who proposed that a pain reduction of approximately two points on the NRS represents a clinically important difference, 34 percent of the patients showed an improvement of clinical importance at the end of the treatment. With approximately 37 percent, this ratio of clinically important improvement was stable to one year after the treatment.

There was a positive effect on the appraisal of affective pain qualities. Although the effect directly after the treatment $(d=0.29)$ was smaller than that in previous studies (e.g., Pieh et al. [24]: $d=0.7$; Hampel et al. [21]: $d=0.55$ ) as was the effect at 6-month follow-up ( $d=0.24$ vs. $d=0.37$ in Hampel et al. [21]), the appraisal of affective pain qualities improved further over time and reached an effect size of $d=0.44$ at twelve months after completion of the treatment. It emphasizes that the treatment may have initiated a process of reappraisal that continued and intensified even further after completion.

In contrast to Pieh et al. [24], the current treatment caused no significant changes regarding the Sensory scale of the Pain Perception Scale. In the study by Hampel et al. [21], there was a significant but small improvement $(d=0.25)$ that diminished after six months. Hammes et al. [36] concluded that treatment (acupuncture in their study) in patients with high chronic pain preferentially improves the affective dimension of pain. With reference to Von Korffs' chronic pain grades [29], the majority of the patients in this study can be described as highly chronic.

The reduction of depressive symptoms at the end of the treatment $(d=0.53)$ was comparable to some previous studies (e.g., Pieh et al. [24]: $d=0.54$; Hampel et al. [21]: $d=0.57$; Ruscheweyh et al. [26]: $d=0.42$ ) but smaller than that observed by Borys et al. [17] $(d=0.77)$, Moradi et al. [22] $(d=0.7)$, and Pöhlmann et al. [25] $(d=0.80)$. In contrast to Borys et al. [17], Hampel et al. [21], and Ruscheweyh et al. [26] who reported that depression rates at follow-up (twelve months and six months, resp.) were no longer different from pretreatment, the reduction in symptoms of depression was significant at twelve-month follow-up in the current study $(d=0.38)$. The effect size for depression at 6-month follow-up $(d=0.45)$, however, was lower than the effect sizes reported by Moradi et al. [22] and Pöhlmann et al. [25] (both $d=0.7$ ). Compared with Schütze et al. [27] $(d=0.10-0.20)$ and Ruscheweyh et al. [26] $(d=0.26)$, the improvement at posttreatment regarding symptoms of anxiety represents a slightly higher effect $(d=0.40)$. Compared to Borys et al. [17] $(d=0.55)$, however, the effect on anxiety at discharge was lower. At 12 -month follow-up, anxiety improved $(d=0.34)$ slightly more than that in Borys et al. [17] $(d=0.22)$. Anxiety at 12 -month follow-up was not different from baseline in the study by Ruscheweyh et al. [26]. The effect sizes for anxiety at the 6-month and 12-month follow-ups were between 0.2 and 0.3 in the study by Schütze et al. [27]. Corresponding to a previous study that documents a high prevalence of depression in chronic pain patients attending treatment [37], depression was the most prevalent comorbidity in the current sample. 
4.1. Limitations and Strengths. The data of the current study were collected in a naturalistic setting. This enhances the external validity of the results. But as the study was neither randomized nor controlled, the internal validity of the results is limited. Therefore, we cannot exclude confounders like time effects as possible causes for the found improvements. Yet, a 4-year follow-up study on the course of chronic pain in the community reported that chronic pain shows low recovery rates [38]. Nevertheless, aspects within and outside the treatment could have influenced our effects, and we cannot conclude what component of the treatment was effective, which components of the treatment contributed the most, or whether a single modal treatment would have had similar effects. However, it should be kept in mind that RCTs and component studies are difficult to realize under the conditions of routine care. Moreover, no information regarding potential treatments during the 12-month followup was available. A strength of the current study is the relatively low dropout rate $(<50 \%$ for each questionnaire at 12-month follow-up). Moreover, the use of multilevel models for discontinuous change in order to evaluate the progress of the outcome variables is a strength of the current study as it is more flexible than the most commonly used repeated measures analysis of variance (ANOVA). Further strengths comprise the several follow-up assessments and the use of psychometrically sound questionnaires. Another limitation is that attendance rates were not recorded so that we could not analyze how many patients received the complete treatment and how the attendance might be correlated with the outcome.

\section{Conclusions}

As chronic pain is most probably caused by an interaction of biopsychosocial factors, multimodal pain treatment programs seem to provide the most effective therapy. The current study supports the notion that chronic pain patients benefit from multimodal treatments under the conditions of routine care in the long term.

\section{Disclosure}

Mira A. Preis and Elisabeth Vögtle share the first authorship.

\section{Conflicts of Interest}

The authors declare that they have no conflicts of interest.

\section{References}

[1] Ó. A. Steingrímsdóttir, T. Landmark, G. J. Macfarlane, and C. S. Nielsen, "Defining chronic pain in epidemiological studies: a systematic review and meta-analysis," PAIN, vol. 158, no. 11, pp. 2092-2107, 2017.

[2] B. Morlion, H. Walch, G. Yihune et al., "The Pain Associates' International Network Initiative: a novel practical approach to the challenge of chronic pain management in Europe," Pain Practice, vol. 8, no. 6, pp. 473-480, 2008.

[3] T. H. Hansson and E. K. Hansson, "The effects of common medical interventions on pain, back function, and work resumption in patients with chronic low back pain: a prospective 2-year cohort study in six countries," Spine, vol. 25, no. 23, pp. 3055-3064, 2000.

[4] A. S. Patel, R. Farquharson, D. Carroll et al., "The impact and burden of chronic pain in the workplace: a qualitative systematic review: systematic review of chronic pain in work or employment," Pain Practice, vol. 12, no. 7, pp. 578-589, 2012.

[5] R. Severeijns, J. W. S. Vlaeyen, M. A. van den Hout, and H. S. J. Picavet, "Pain catastrophizing is associated with health indices in musculoskeletal pain: a cross-sectional study in the Dutch community," Health Psychology, vol. 23, no. 1, pp. 49-57, 2004.

[6] GBD 2016 Disease and Injury Incidence and Prevalence Collaborators, "Global, regional, and national incidence, prevalence, and years lived with disability for 328 diseases and injuries for 195 countries, 1990-2016: a systematic analysis for the Global Burden of Disease Study 2016," The Lancet, vol. 390, no. 10100, pp. 1211-1259, 2017.

[7] H. Lee, M. Hübscher, G. L. Moseley et al., "How does pain lead to disability? A systematic review and meta-analysis of mediation studies in people with back and neck pain," PAIN, vol. 156, no. 6, pp. 988-997, 2015.

[8] L. A. McWilliams, B. J. Cox, and M. W. Enns, "Mood and anxiety disorders associated with chronic pain: an examination in a nationally representative sample," Pain, vol. 106, no. 1, pp. 127-133, 2003.

[9] L. A. McWilliams, R. D. Goodwin, and B. J. Cox, "Depression and anxiety associated with three pain conditions: results from a nationally representative sample," Pain, vol. 111, no. 1, pp. 77-83, 2004.

[10] H. Flor, T. Fydrich, and D. C. Turk, "Efficacy of multidisciplinary pain treatment centers: a meta-analytic review," Pain, vol. 49, no. 2, pp. 221-230, 1992.

[11] J. Guzmán, R. Esmail, K. Karjalainen, A. Malmivaara, E. Irvin, and C. Bombardier, "Multidisciplinary rehabilitation for chronic low back pain: systematic review," BMJ, vol. 322, no. 7301, pp. 1511-1516, 2001.

[12] S. J. Kamper, A. T. Apeldoorn, A. Chiarotto et al., "Multidisciplinary biopsychosocial rehabilitation for chronic low back pain," in Cochrane Database of Systematic Reviews, The Cochrane Collaboration, Ed., John Wiley \& Sons, Ltd., Chichester, UK, 2014.

[13] T. Kennedy-Martin, S. Curtis, D. Faries, S. Robinson, and J. Johnston, "A literature review on the representativeness of randomized controlled trial samples and implications for the external validity of trial results," Trials, vol. 16, no. 1, 2015.

[14] G. T. Jones, E. A. Jones, M. J. Beasley, and G. J. Macfarlane, "Investigating generalizability of results from a randomized controlled trial of the management of chronic widespread pain: the MUSICIAN study," PAIN, vol. 158, no. 1, pp. 96$102,2017$.

[15] F. Leichsenring, "Randomized controlled versus naturalistic studies: a new research agenda," Bulletin of the Menninger Clinic, vol. 68, no. 2, pp. 137-151, 2004.

[16] J. Artner, S. Kurz, B. Cakir, H. Reichel, and F. Lattig, "Intensive interdisciplinary outpatient pain management program for chronic back pain: a pilot study," Journal of Pain Research, vol. 2012, no. 5, pp. 209-216, 2012.

[17] C. Borys, J. Lutz, B. Strauss, and U. Altmann, "Effectiveness of a multimodal therapy for patients with chronic low back pain regarding pre-admission healthcare utilization," PLoS One, vol. 10, no. 11, p. ee0143139, 2015.

[18] E. Dysvik, J. T. Kvaløy, R. Stokkeland, and G. K. Natvig, "The effectiveness of a multidisciplinary pain management programme managing chronic pain on pain perceptions, health- 
related quality of life and stages of change-a non-randomized controlled study," International Journal of Nursing Studies, vol. 47, no. 7, pp. 826-835, 2010.

[19] E. Dysvik, J. T. Kvaløy, and G. K. Natvig, "The effectiveness of an improved multidisciplinary pain management programme: a 6- and 12-month follow-up study," Journal of Advanced Nursing, vol. 68, no. 5, pp. 1061-1072, 2012.

[20] I. C. Fedoroff, E. Blackwell, and B. Speed, "Evaluation of group and individual change in a multidisciplinary pain management program," Clinical Journal of Pain, vol. 30, no. 5, pp. 399-408, 2014.

[21] P. Hampel, A. Brunnberg, B. Krohn-Grimberghe et al., "Schmerzchronifizierung, geschlecht und rehabilitationserfolg bei chronischem rückenschmerz: eine pilotstudie," Der Orthopäde, vol. 38, no. 8, pp. 742-751, 2009.

[22] B. Moradi, S. Hagmann, A. Zahlten-Hinguranage et al., "Efficacy of multidisciplinary treatment for patients with chronic low back pain: a prospective clinical study in 395 patients," Journal of Clinical Rheumatology, vol. 18, no. 2, pp. 76-82, 2012.

[23] E. Neubauer, A. Zahlten-Hinguranage, M. Schiltenwolf, and M. Buchner, "Multimodale therapie bei chronischem HWSund LWS-schmerz. Ergebnisse einer prospektiven vergleichsstudie," Schmerz, vol. 20, no. 3, pp. 210-218, 2006.

[24] C. Pieh, S. Neumeier, T. Loew et al., "Effectiveness of a multimodal treatment program for somatoform pain disorder," Pain Practice, vol. 14, no. 3, pp. E146-E151, 2014.

[25] K. Pöhlmann, T. Tonhauser, P. Joraschky, and B. Arnold, "Die Multimodale Schmerztherapie Dachau (MSD): daten zur wirksamkeit eines diagnose-unabhängigen multimodalen therapieprogramms bei rückenschmerzen und anderen schmerzen," Schmerz, vol. 23, no. 1, pp. 40-46, 2009.

[26] R. Ruscheweyh, K. Dany, M. Marziniak, and I. Gralow, "Basal pain sensitivity does not predict the outcome of multidisciplinary chronic pain treatment," Pain Medicine, vol. 16, no. 8, pp. 1635-1642, 2015.

[27] A. Schütze, U. Kaiser, U. Ettrich et al., "Evaluation einer multimodalen schmerztherapie am universitätsschmerzcentrum Dresden," Schmerz, vol. 23, no. 6, pp. 609-617, 2009.

[28] I. R. Wilson, "Management of chronic pain through pain management programmes," British Medical Bulletin, vol. 124, no. 1, pp. 55-64, 2017.

[29] M. Von Korff, J. Ormel, F. J. Keefe, and S. F. Dworkin, "Grading the severity of chronic pain," PAIN, vol. 50, no. 2, pp. 133-149, 1992.

[30] E. Geissner, "Die schmerzempfindungsskala SES-E in differenziertes und veränderungssensitives verfahren zur erfassung chronischer und akuter schmerzen," Rehabilitation, vol. 34, no. 4, pp. 35-43, 1995.

[31] C. Herrmann-Lingen, U. Buss, and P. Snaith, "Hospital Anxiety and Depression Scale-Deutsche Version (HADS-D)," Zeitschrift für Psychiatrie, Psychologie und Psychotherapie, vol. 59, no. 3, pp. 251-253, 2011.

[32] A. S. Zigmond and R. P. Snaith, "The Hospital Anxiety and Depression Scale," Acta Psychiatrica Scandinavica, vol. 67, no. 6, pp. 361-370, 1983.

[33] H.-D. Basler and B. Kröner-Herwig, Psychologische Therapie bei Kopf- und Rückenschmerzen: Das Marburger Schmerzbewältigungsprogramm Zur Gruppen- und Einzeltherapie, München: Quintessenz, 1998.

[34] R. Göllner, M. Gollwitzer, J. Heider, A. Zaby, and A. Schröder, "Auswertung von längsschnittdaten mit hierarchisch-linearen modellen," Zeitschrift für Klinische Psychologie und Psychotherapie, vol. 39, no. 3, pp. 179-188, 2010.
[35] J. T. Farrar, J. P. Young, L. LaMoreaux, J. L. Werth, and R. M. Poole, "Clinical importance of changes in chronic pain intensity measured on an 11-point numerical pain rating scale," PAIN, vol. 94, no. 2, pp. 149-158, 2001.

[36] M. G. Hammes, B. Flatau, M. Bäcker, S. Ehinger, B. Conrad, and T. R. Tölle, "Wirkung der akupunktur auf die affektive und sensorische schmerzbewertung," Schmerz, vol. 16, no. 2, pp. 103-113, 2002.

[37] L. Rayner, M. Hotopf, H. Petkova, F. Matcham, A. Simpson, and L. M. McCracken, "Depression in patients with chronic pain attending a specialised pain treatment centre: prevalence and impact on health care costs," PAIN, vol. 157, no. 7, pp. 1472-1479, 2016.

[38] A. M. Elliott, B. H. Smith, P. C. Hannaford, W. C. Smith, and W. A. Chambers, "The course of chronic pain in the community: results of a 4-year follow-up study," Pain, vol. 99, no. 1, pp. 299-307, 2002 


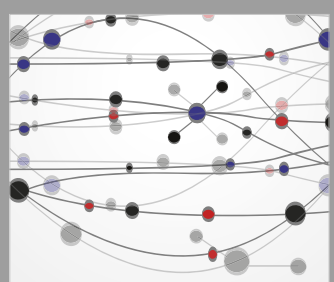

The Scientific World Journal
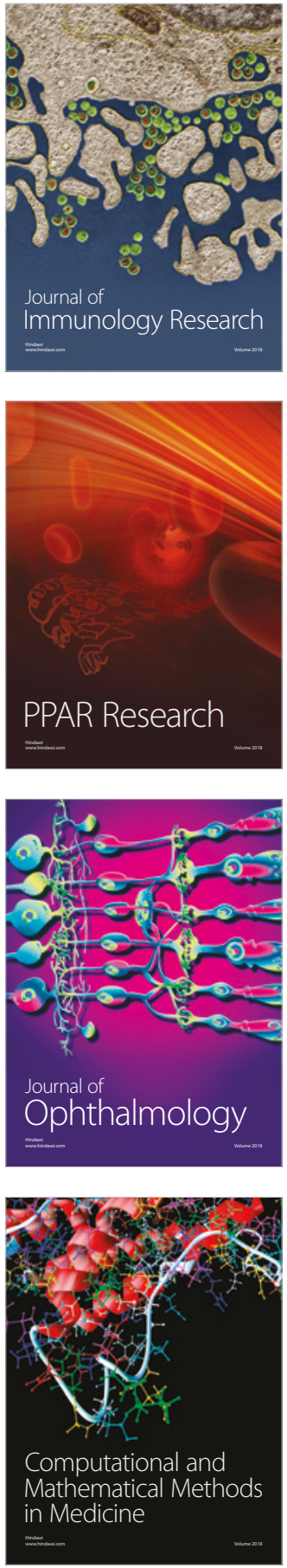

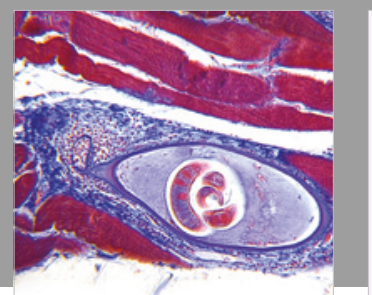

Gastroenterology Research and Practice

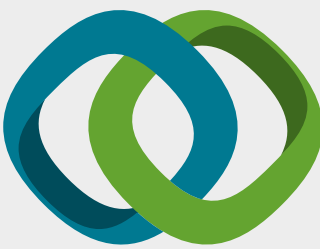

\section{Hindawi}

Submit your manuscripts at

www.hindawi.com
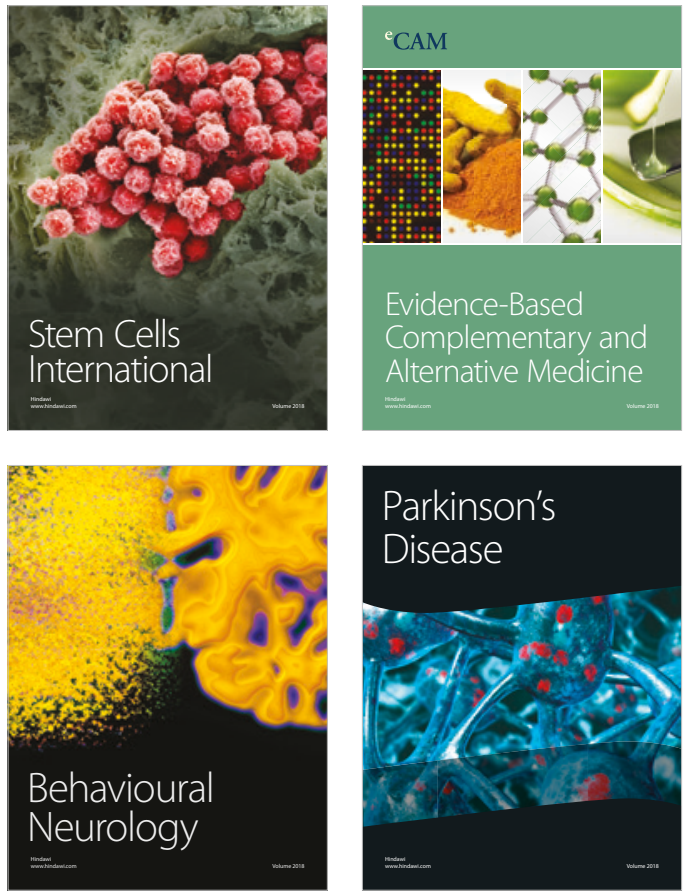

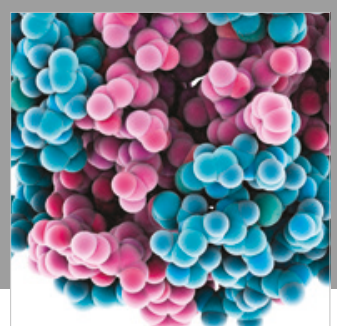

ournal of

Diabetes Research

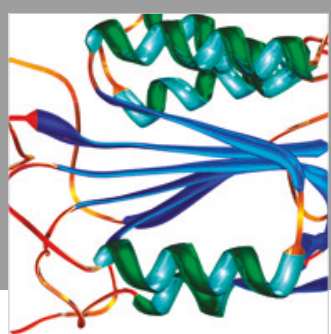

Disease Markers
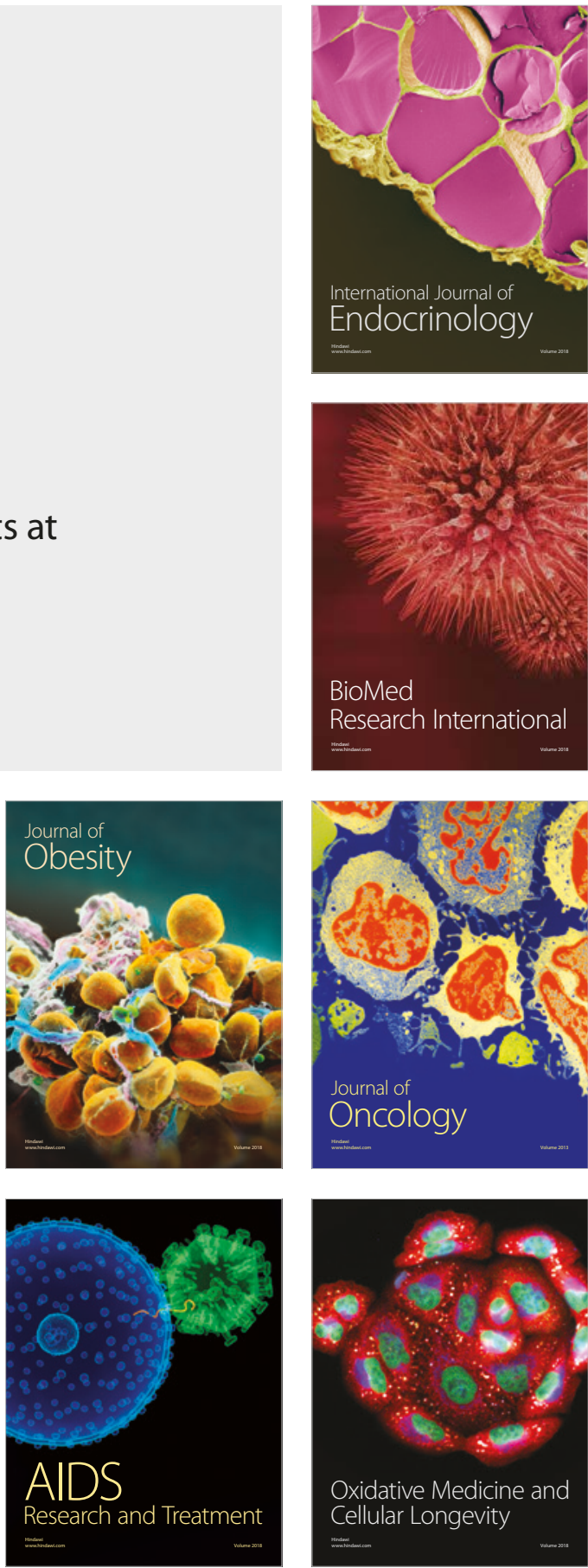